\title{
Neuron-Specific Alterations in Signal Transduction Pathways associated with Alzheimer's Disease
}

\author{
Anne Gerschütz ${ }^{\mathrm{a}}$, Helmut Heinsen ${ }^{\mathrm{b}}$, Edna Grünblatt ${ }^{\mathrm{c}}$, Anne Kristin Wagner ${ }^{\mathrm{a}}$, Jasmin Bartl ${ }^{\mathrm{c}}$, \\ Christoph Meissner ${ }^{\mathrm{d}}$, Andreas J. Fallgatter ${ }^{\mathrm{e}}$, Safa Al-Sarraj ${ }^{\mathrm{f}}$, Claire Troakes $^{\mathrm{f}}$, Isidro Ferrer ${ }^{\mathrm{g}}$, \\ Thomas Arzberger $^{\mathrm{h}}$, Jürgen Deckert ${ }^{\mathrm{b}}$, Peter Riederer ${ }^{\mathrm{b}}$, Matthias Fischer ${ }^{\mathrm{b}}$, Thomas Tatschner ${ }^{\mathrm{i}}$ \\ and Camelia Maria Monoranu ${ }^{\mathrm{a}, *}$ \\ ${ }^{a}$ Department of Neuropathology, Institute of Pathology, University of Wuerzburg, Wuerzburg, Germany \\ ${ }^{\mathrm{b}}$ University Hospital, Clinic and Policlinic for Psychiatry, Psychosomatic and Psychotherapy, \\ University of Wuerzburg, Wuerzburg, Germany \\ ${ }^{\mathrm{c}}$ Clinic of Child and Adolescent Psychiatry, University of Zurich, Zurich, Switzerland \\ ${ }^{\mathrm{d}}$ Department of Forensic Medicine, University of Schleswig-Holstein, Luebeck, Germany \\ ${ }^{\mathrm{e}}$ Clinic and Policlinic for Psychiatry and Psychotherapy, University of Tuebingen, Tuebingen, Germany \\ ${ }^{\mathrm{f}}$ MRC London Neurodegenerative Diseases Brain Bank, King's College London, London, UK \\ ${ }^{\mathrm{g}}$ Institut de Neuropatologia, Seervei Anatomia Patologica, IDIBELL-Hospital Universitari de Bellvitge, \\ Barcelona, Spain \\ ${ }^{\mathrm{h}}$ Institute of Neuropathology and Prion Research, University of Munich, Munich, Germany \\ ${ }^{\mathrm{i}}$ Institute of Legal Medicine, University of Wuerzburg, Wuerzburg, Germany
}

\begin{abstract}
The hallmarks of sporadic Alzheimer's disease (AD) are extracellular amyloid deposits, intracellular neurofibrillary tangles (NFTs), and neuronal death. Hyperphosphorylation of tau is a key factor in the generation of NFTs. Mitogen activated protein kinase 1 (MAPK1) and protein kinase $\mathrm{C}$ beta $(\mathrm{PRKCB})$ are thought to play a role in hyperphosphorylation, and $\mathrm{PRCKB}$ is thought to be involved in hypoxic stress and vascular dysfunction, and to trigger MAPK phosphorylation pathways. We performed single-cell analyses of neurons with different vulnerabilities to AD-related changes. Using quantitative PCR (qPCR), we measured the levels of MAPK1 and PRKCB transcript in CA1 (high vulnerability), CA2 pyramidal cells from the hippocampus, granule cells from the cerebellum (low vulnerability), and neurons from the brain stem (nucleus tractus spinalis nervi trigemini, characterized by early neurophysiological deficits) at progressive Braak stages compared to age-matched controls. The highly vulnerable CA1 pyramidal neurons were characterized by age- and disease-unrelated increases in PRCKB levels and by age- and disease-related increases in MAPK1 levels. In contrast, low PRKCB levels were found in CA2 pyramidal neurons, and MAPK1 levels were elevated in controls and intermediate AD stages. Both PRKCB and MAPK1 were increased in the late AD stages. MAPK1 and PRKCB levels were low in the brainstem and cerebellum. We propose that alterations in the expression of these two genes occur early in the pathogenesis of $\mathrm{AD}$ in a region-specific manner. In addition, multiple signal transduction pathways need to be affected to result in $\mathrm{AD}$ instead of physiological aging.
\end{abstract}

Keywords: Alzheimer's disease, MAPK1, neurodegeneration, PRKCB, selective vulnerability, signal transduction pathway

${ }^{*}$ Correspondence to: Camelia Maria Monoranu, Department of Neuropathology, Institute of Pathology, University of Wuerzburg, Josef-Schneider-Str. 2, 97080 Würzburg, Germany. Tel.: +49 931 3181478; E-mail: camelia-maria.monoranu@mail.uni-wuerzburg. de. 


\section{INTRODUCTION}

The neuropathological criteria for $\mathrm{AD}$ comprise extracellular amyloid deposits, intracellular neurofibrillary tangles (NFTs), and neuron loss. NFTs propagate in an anatomically stereotypical manner, allowing classification into different AD stages [1]. Closely related areas or fields within circumscribed regions exhibit different susceptibilities to neuropathological changes. The CA1 region of the hippocampus is especially vulnerable to $\mathrm{AD}$-related changes, whereas the nearby $\mathrm{CA} 2$ region $[1,2]$ displays no significant loss of pyramidal cells during AD development [3]. The cerebellum is nearly devoid of NFTs and prone to amyloid deposits, particularly in the molecular layer [4-6]. Involvement of the brainstem in AD is controversial. Some studies have reported that certain nuclei of the brain stem are affected early in AD [7-9], but other studies did not find evidence that AD progresses from the subcortical to cortical brain regions [10]. A diagnostic method for detecting AD in its early stages uses vagus-evoked somatosensory potentials $[11,12]$. The auricular branch of the vagus nerve is composed of sensory fibers, some of which end in the nucleus tractus spinalis nervi trigemini and are stimulated via electric potentials [13]. Individuals with dementia demonstrate longer latencies compared to age-matched controls, suggesting involvement of the nucleus tractus spinalis nervi trigemini in the development of AD.

The propensity of neuronal cells and regions to react differently to identical pathogenic challenges was called pathoklisis by Vogt and Vogt [14]. According to the authors, pathoklisis represents a concept in the study of the reaction of normal neurons to pathological events. In our special case, we wanted to unravel the potential molecular mechanisms underlying the emergence of tau pathology.

The reasons for the selective vulnerability of certain brain regions and within individual cell types are still unknown. We focused on two important components of signal transduction pathways that are associated with early $\mathrm{AD}$ development: mitogen-activated protein kinase 1 (MAPK1) and protein kinase $\mathrm{C}$ beta (PRKCB). MAPKs are serinethreonine kinases involved in the mediation of cellular responses, including cell proliferation, differentiation, cell survival, and apoptosis. The mammalian MAPK family includes extracellular signal-regulated kinases (MAPK1, MAPK2), p38, and c-Jun NH2-terminal kinase (JNK). Each of these kinases is capable of phosphorylating tau protein. MAPK1 mRNA and activated protein levels are upregulated in the hippocampus in
AD [15-17], implicating MAPK1 in the formation of hyperphosphorylated tau protein early in the development of AD.

Protein kinase C (PKC) comprises a family of related serine-threonine kinases. One isoform, PRKCB, is fully activated through the second messengers $\mathrm{CA}^{2+}$ and diacylglycerol (DAG), and deficits in signaling are linked to $\mathrm{AD}$ progression. Divergent opinions exist regarding the involvement of PRKCB in $\mathrm{AD}$ development. Some investigators have reported deficiencies in PKC activation [18, 19], whereas others have reported an increase in phosphorylated PKC [20].

Using single-cell laser microdissection, we examined mRNA levels in neurons from the CA1 and CA2 regions of the hippocampus, nucleus tractus spinalis nervi trigemini of the brain stem, and cerebellum of $\mathrm{AD}$ patients. The measurements were compared to agematched controls in order to obtain new insights into the pathogenesis and progression of $\mathrm{AD}$.

\section{METHODS}

\section{Tissue samples}

Frozen brain tissue (hippocampus, brain stem, and cerebellum) from patients clinically and neuropathologically diagnosed with different stages of $\mathrm{AD}$ and age-matched controls were provided by four different Brain Bank Centers (Wuerzburg, Munich, King's College London, and Barcelona). All tissue banks are members of the BrainNet Europe Brain Bank Consortium Network (http://www.brainnet-europe.org/). The tissue samples were snap-frozen on dry ice. Samples were categorized as controls ( $n=9$; no neuropathologically diagnosed Braak stages or Braak stage I), intermediate $\mathrm{AD}(n=11$; Braak stages III-IV), or late $\mathrm{AD}(n=9$; Braak stages V-VI). The postmortem intervals (PMIs) varied from 2 to $72 \mathrm{~h}$ but were not significantly different between groups: mean \pm standard deviation (SD) $26.1 \pm 21.8 \mathrm{~h}$ in the control group, $32.0 \pm 16.7 \mathrm{~h}$ in the intermediate $\mathrm{AD}$ group, and $26.5 \pm 12.3 \mathrm{~h}$ in the late $\mathrm{AD}$ group. The age range was 62-80 years in controls, 64-92 years in the intermediate $\mathrm{AD}$ group, and 56-86 years in the late $\mathrm{AD}$ group. Significant age differences were found between the control and intermediate AD groups $(69.2 \pm 5.0$ years versus $79.5 \pm 7.1$ years, $p<0.0001)$ and between the intermediate and late $\mathrm{AD}$ groups $(79.5 \pm 7.1$ years versus $72.2 \pm 9.6$ years, $p=0.0001)$. Demographic details are provided in Table 1 . The study was approved by the local ethics committee (Application Number 99/11) and was performed in accordance with the ethical 
Table 1

Sample characteristics

\begin{tabular}{|c|c|c|c|c|c|c|}
\hline \multirow{2}{*}{$\begin{array}{l}\text { No. } \\
1\end{array}$} & \multirow{2}{*}{$\frac{\text { Group }}{\text { Control }}$} & \multicolumn{2}{|c|}{ Age (y) PMI (h) } & \multirow{2}{*}{$\begin{array}{c}\text { Gender } \\
\mathrm{m}\end{array}$} & \multicolumn{2}{|c|}{ Braak stage RIN } \\
\hline & & 80 & 23 & & I & 6.4 \\
\hline 2 & Control & 70 & 40 & $\mathrm{f}$ & I & 6.8 \\
\hline 3 & Control & 62 & 48 & $\mathrm{f}$ & I & 6.3 \\
\hline 4 & Control & 68 & 11 & $\mathrm{~m}$ & I & 5.8 \\
\hline 5 & Control & 70 & 2 & $\mathrm{~m}$ & I & 7.6 \\
\hline 6 & Control & 67 & 15 & $\mathrm{~m}$ & I & 6.9 \\
\hline 7 & Control & 64 & 9 & $\mathrm{~m}$ & I & 6.1 \\
\hline 8 & Control & 73 & 16 & $\mathrm{f}$ & I & 5.6 \\
\hline 9 & Control & 69 & 72 & $\mathrm{~m}$ & - & 6.7 \\
\hline Mean & - & 69.2 & 26.1 & $\mathrm{f} / \mathrm{m}=0.5$ & $-/ \mathrm{I}$ & 6.5 \\
\hline SD & - & $5.0^{* *}$ & 21.8 & - & - & 0.6 \\
\hline 10 & Intermediate $\mathrm{AD}$ & 77 & 24 & $f$ & III & 6.3 \\
\hline 11 & Intermediate $\mathrm{AD}$ & 78 & 38 & $f$ & IV & 6.6 \\
\hline 12 & Intermediate $\mathrm{AD}$ & 75 & 20 & $f$ & III & 6.5 \\
\hline 13 & Intermediate $\mathrm{AD}$ & 85 & 46 & $\mathrm{f}$ & III & 5.9 \\
\hline 14 & Intermediate $\mathrm{AD}$ & 64 & 24 & $\mathrm{~m}$ & III & 6.6 \\
\hline 15 & Intermediate $\mathrm{AD}$ & 80 & 60 & $\mathrm{~m}$ & III & 6.2 \\
\hline 16 & Intermediate $\mathrm{AD}$ & 92 & 20 & $\mathrm{f}$ & III & 4.8 \\
\hline 17 & Intermediate $\mathrm{AD}$ & 85 & 25 & $\mathrm{~m}$ & IV & 5.6 \\
\hline 18 & Intermediate $\mathrm{AD}$ & 86 & 61 & $\mathrm{f}$ & III & 5.4 \\
\hline 19 & Intermediate $\mathrm{AD}$ & 76 & 6 & $\mathrm{~m}$ & III & 5.8 \\
\hline 20 & Intermediate $\mathrm{AD}$ & 77 & 28 & $\mathrm{f}$ & III & 5.1 \\
\hline Mean & - & 79.5 & $32.0 \quad 1$ & $\mathrm{f} / \mathrm{m}=1.75$ & III-IV & 5.9 \\
\hline SD & - & 7.1 & 16.7 & - & - & 0.6 \\
\hline 21 & Late AD & 74 & 26 & $f$ & $\mathrm{~V}$ & 5.1 \\
\hline 22 & Late AD & 65 & 24 & $f$ & V & 4.8 \\
\hline 23 & Late AD & 80 & 24 & $f$ & VI & 6.8 \\
\hline 24 & Late AD & 83 & 22 & $\mathrm{f}$ & VI & 6.0 \\
\hline 25 & Late AD & 70 & 39 & $\mathrm{~m}$ & VI & 5.2 \\
\hline 26 & Late AD & 62 & n.a. & $\mathrm{m}$ & VI & 6.5 \\
\hline 27 & Late AD & 74 & 50 & $\mathrm{~m}$ & VI & 5.4 \\
\hline 28 & Late AD & 86 & 21 & $\mathrm{f}$ & VI & 7.2 \\
\hline 29 & Late AD & 56 & 7 & f & VI & 5.1 \\
\hline Mean & - & 72.2 & 26.5 & $\mathrm{f} / \mathrm{m}=2$ & V-VI & 5.8 \\
\hline SD & - & $9.6^{* *}$ & 12.3 & - & - & 0.9 \\
\hline
\end{tabular}

AD, Alzheimer's disease; f, female; m, male; n.a., not available; PMI, postmortem interval; RIN, RNA integrity number; SD, standard deviation. ${ }^{* *} p<0.001$ versus Intermediate AD using ANOVA with post-hoc Scheffe test.

standards described in the most recent version of the Declaration of Helsinki.

\section{Tissue quality}

Various factors, including long PMI intervals, can lead to a reduction in tissue, and consequently RNA, quality. To analyze RNA quality, total RNA was extracted from $2-3$ brain slices $(10-\mu \mathrm{m}$ thickness) for each included case using the RNeasy Min Elute Cleanup Kit (Qiagen, Hilden, Germany). The RNA concentration was measured using a spectrophotometer (Nanodrop 1000, Peqlab, Erlangen, Germany). A $2-\mu l$ aliquot of the isolated RNA was delivered to the Microarray Core Unit in Wuerzburg. The RNA integrity number (RIN) was determined using an Agilent 2100 Bioanalyzer (Agilent Technologies, Boeblingen, Germany). Only cases with a RIN close to or higher than 5 were included in the study to ensure sufficient RNA quality.

\section{Sample preparation for laser microdissection}

Ten-micrometer sections were cut from each brain region using a CM1950 cryostat (Leica, Wetzlar, Germany) at $-15^{\circ} \mathrm{C}$, and then mounted on polyester membranes (Leica, Wetzlar, Germany) and stained with cresyl violet as follows. The sections were fixed for $2 \mathrm{~min}$ in $70 \% \mathrm{EtOH}$, stained in $1 \%$ cresyl violet for $1 \mathrm{~min}$, and washed in $70 \%$ and $100 \% \mathrm{EtOH}$. The slides were allowed to dry completely in a desiccator for $45 \mathrm{~min}$ and then used directly for laser microdissection or stored at $-80^{\circ} \mathrm{C}$ until needed for further processing.

\section{Laser microdissection and cDNA synthesis}

The slides were used for laser microdissection on a LMD6000 microscope (Leica). In each case, a total of 150 pyramidal cells from the CA1 and CA2 regions of the hippocampus, 500 neurons from among the diverse neuronal types of the nucleus tractus spinalis nervi trigemini of the brain stem, and 500 cerebellar granule cells respectively were laser microdissected. Next, $4.7 \mu \mathrm{l}$ of a combined cell lysis and cDNA synthesis reaction mix consisting of $1 \mathrm{mM}$ Tris/ $\mathrm{HCl}(\mathrm{pH}$ 8.0), 0.2 mM dNTPs (VWR, Darmstadt, Germany), 0.1 mM Random Primer N6 (Roche, Mannheim, Germany), $1 \times$ First Strand Buffer (Invitrogen, Darmstadt, Germany), $10 \mathrm{mM}$ dithiothreitol (Life Technologies, Darmstadt, Germany), 0.5\% Nonident P40 (Roche), $20 \mu \mathrm{g}$ glycogen (Fermentas, St. Leon-Rot, Germany), and 5 Units RNasin Plus RNase Inhibitor (Promega, Mannheim, Germany) was added directly to the cells following a modification of the protocol described by Grundemann et al. [21]. The cap was incubated upside down for $2 \mathrm{~min}$ at $72^{\circ} \mathrm{C}$ and then $1 \mathrm{~min}$ on ice, followed by centrifugation for $1 \mathrm{~min}$ at full speed. Superscript III reverse transcriptase $(60 \mathrm{U}$ in $0.3 \mu \mathrm{l}$ ) was added to each reaction. The cDNA synthesis was performed for $2 \mathrm{~h}$ at $38^{\circ} \mathrm{C}$ and $8 \mathrm{~h}$ at $39^{\circ} \mathrm{C}$ in a final volume of $5 \mu \mathrm{l}$. The cDNA was stored at $-20^{\circ} \mathrm{C}$.

\section{Real-time quantitative polymerase chain reaction (qPCR)}

The qPCR reactions were carried out using $1 \mu \mathrm{l}$ diluted cDNA (1:10), Gene Expression MasterMix 
(Life Technologies), and predesigned TaqMan assays (Life Technologies, Darmstadt, Germany) in a total volume of $13 \mu \mathrm{l}$ in a CFX $\mathrm{C} 1000^{\mathrm{TM}}$ real time system (BioRad, Muenchen, Germany). The TaqMan assays were MAPK1 (Life Technologies, Hs01046830_m1) and PRKCB (Life Technologies, Hs00176998_m1). A multiple gene set was included to allow the detection of suitable reference genes for normalization: glyceraldehyde-3-phosphate dehydrogenase (GAPDH; Life Technologies, Hs99999905_m1), solute carrier family 1 member 3 (SLC1A3; Life Technologies, Hs00188193_m1), mitochondrial single-stranded DNA binding protein 1 (SSBP1; Life Technologies, Hs00995378_m1), TAO kinase 3 (TAOK3; Life Technologies, Hs00937694_m1), TATA box binding protein (TBP; Life Technologies, Hs00427620_m1), transmembrane 9 superfamily protein member 4 (TM9SF4; Life Technologies, Hs00207196_m1), TM2 domain containing 1 (TM2D1; Life Technologies, Hs00608855_m1), and zinc finger protein 445 (ZNF445; Life Technologies, Hs00412938_m1). All assays were FAM-labeled, and only intron-spanning assays were used to avoid the detection of genomic DNA. Each assay included a negative cDNA synthesis reaction without reverse transcriptase that resulted in no detectable signals after qPCR (data not shown). The run conditions consisted of an initial phase of $50^{\circ} \mathrm{C}$ for $2 \mathrm{~min}, 95^{\circ} \mathrm{C}$ for $10 \mathrm{~min}$, and 50 cycles including a $15 \mathrm{~s}$ denaturation step at $95^{\circ} \mathrm{C}$ and primer annealing and elongation for $1 \mathrm{~min}$ at $60^{\circ} \mathrm{C}$. Each sample was tested in triplicate with mean values calculated at the end of the run. Technical replicates of different dilutions were performed to test the acceptable variations between the Cq-values of one sample when using a low concentration of cDNA. Non-template controls were included that resulted in no signals. For normalization, the individual PCR efficiency of each primer pair was defined using LinReg [22] (Table 2). GeNorm (http://medgen.ugent.be/jvdesomp/genorm/) was used to detect the most stable reference genes. GAPDH and TM2D1 displayed the lowest M-values (both 0.678) and were used as reference genes for normalization. After calculating the geometric averages of the quantities of the reference genes for each sample, the normalized expression levels were assessed by dividing the quantities of the gene of interest for each sample by the corresponding normalization factor generated by GeNorm (Microsoft Excel 2007). Samples with no qPCR signal for reference or target genes and samples with a variation higher than 2-SD were defined as outliers and excluded from analysis.
Table 2

PCR efficiency determined by LinReg

\begin{tabular}{lc}
\hline TaqMan assay & PCR efficiency \\
\hline GAPDH & 1.675 \\
MAPK1 & 1.829 \\
PRKCB & 1.774 \\
SLC1A3 & 2.008 \\
SSBP1 & 1.937 \\
TAOK3 & 1.846 \\
TBP & 1.777 \\
TM2D1 & 1.841 \\
TM9SF4 & 1.894 \\
ZNF455 & 1.9 \\
\hline
\end{tabular}

\section{Statistical analysis}

Statistical analysis of MAPK1 and PRKCB expression within the different groups and brain regions was performed using one-way analysis of variance (ANOVA) and the post hoc Scheffe test (StatView 5.0). Significance was set at $p<0.05$.

\section{RESULTS}

\section{$M A P K 1$ expression in age and $A D$}

Because we found significant age differences between the control and intermediate $\mathrm{AD}$ groups, we tested whether an age-related expression pattern exists for MAPK1. No linear correlation was observed between MAPK1 expression and age within the groups using Fisher transformation (data not shown). Figure 1A shows the MAPK1 expression levels in each region by group. Significant differences were observed between groups for only the CA2 pyramidal cells of the hippocampus; MAPK1 expression was significantly higher in the late AD group compared to the control $(p=0.02)$ and intermediate $\operatorname{AD}$ group $(p=0.015)$. Figure 1B shows the MAPK1 expression pattern within the neurons from different brain regions independent of group. MAPK1 expression was significantly higher in CA1 pyramidal cells from the hippocampus than in the granule cells from the cerebellum $(p<0.0001)$ or neurons from the brain stem $(p<0.0001)$. MAPK1 expression was also significantly higher in neurons from the pyramidal layer of the CA2 region compared to granule cells from the cerebellum $(p<0.0001)$ and neurons from the brain stem $(p<0.0001)$. No significant differences were found in MAPK1 expression between neurons from the cerebellum or brain stem or between CA1 and CA2 pyramidal cells. 
Control

A

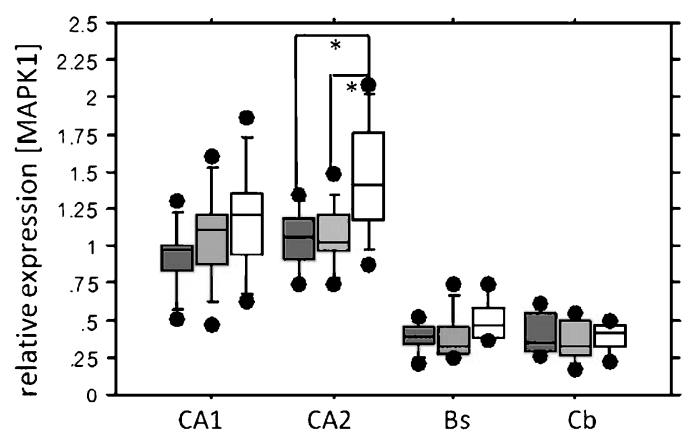

Intermediate $A D$

Late AD

B

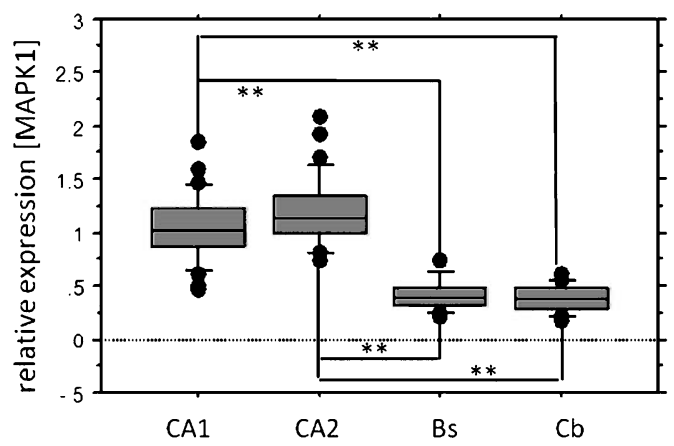

Fig. 1. A) Expression of MAPK1 in granule cells from the cerebellum (Cb), CA1 and CA2 pyramidal cells from the hippocampus (CA1; CA2), and neurons from the nucleus tractus spinalis of the brain stem (Bs) of control (dark grey; $n=8$ for CA1, $n=8$ for CA2, $n=9$ for Bs, and $n=6$ for $\mathrm{Cb}$ ), intermediate $\mathrm{AD}$ (light grey; $n=11$ for CA1, $n=11$ for CA2, $n=8$ for Bs, and $n=9$ for Cb), and late AD (white; $n=8$ for $\mathrm{CA} 1, n=9$ for $\mathrm{CA} 2, n=7$ for $\mathrm{Bs}$, and $n=7$ for $\mathrm{Cb}$ ) groups. (B) Region-specific gene expression levels independent of group ( $n=27$ for $\mathrm{CA} 1, n=28$ for $\mathrm{CA} 2, n=24$ for Bs, and $n=22$ for $\mathrm{Cb}$ ). Error bars indicate standard deviations. Statistical analysis was performed using ANOVA and the post hoc Scheffe test. ${ }^{*} p<0.05,{ }^{* *} p<0.001$.

\section{$P R K C B$ expression in age and $A D$}

We did not detect an age-associated pattern of PRKCB expression between the different groups when using Fisher transformation (data not shown). Figure 2A shows the PRKCB expression levels in each region by group. Significant differences were observed between groups for only the CA2 region of the hippocampus; PRKCB expression was significantly higher in the late $\mathrm{AD}$ group compared to the control $(p=0.045)$ and intermediate $\mathrm{AD}$ groups $(p=0.0005)$. Independent of groups, the highest PRKCB expression was found in the pyramidal cells of the CA1 region (Fig. 2B). PRKCB expression levels were significantly higher in the CA1 pyramidal cells compared to CA2 pyramidal cells $(p<0.0001)$, cerebellar granule cells $(p<0.0001)$, and neurons from the brain stem $(p<0.0001)$. Moreover, PRKCB expression was significantly higher in neurons from the brain stem compared to cerebellar granule cells $(p=0.0355)$. No significant differences in PRKCB expression were found between neurons from the $\mathrm{CA} 2$ region and neurons from the cerebellum or brain stem.

No gender related variations in the expression of MAPK1 and PRKCB were observed (data not shown).

\section{DISCUSSION}

We analyzed the MAPK1 and PRKCB expression in neuronal cell types from different brain regions with selective vulnerability to tau pathology over the course of AD progression. The results suggest that CA1 pyramidal cells express significantly higher levels of MAPK1 and PRKCB transcript compared to the cerebellar and brainstem regions. CA2 pyramidal cells achieve an intermediate position in this ranking, with elevated levels of MAPK1 and low levels of PRKCB. However, data pooling masked the significantly elevated MAPK1 and PRKCB levels in CA2 pyramidal cells in the late stages of AD. Therefore, when combined with the neuropathological observation, the elevated levels of MAPK1 and PRCKB could be hypothesized to play a role in early NFT genesis in CA1 pyramidal cells. The upregulation of both kinases could play a role in NFT genesis in CA2 pyramidal cells, but only in late stages of AD. The brainstem regions with notoriously low levels of both kinases are not prone to AD-related changes. Similarly, the cerebellum is only rarely, if ever, affected by AD-related changes, and no abnormal activation of MAPK1 has been observed in cerebellar tissue [23].

Variations in the expression of components of the essential signal transduction pathways could explain the different susceptibilities of certain cell types to AD-related pathological changes. Previous immunohistochemistry studies have reported an association between phosphorylated MAPK1 and early tau deposition [16]. Pei et al. [17] reported that activated MAPK1 accumulates in neurons without tau pathology as early as Braak stages I and II, analogously increasing with AD progression. MAPKs possess the capacity to phosphorylate tau in vitro and in vivo, and the involvement 


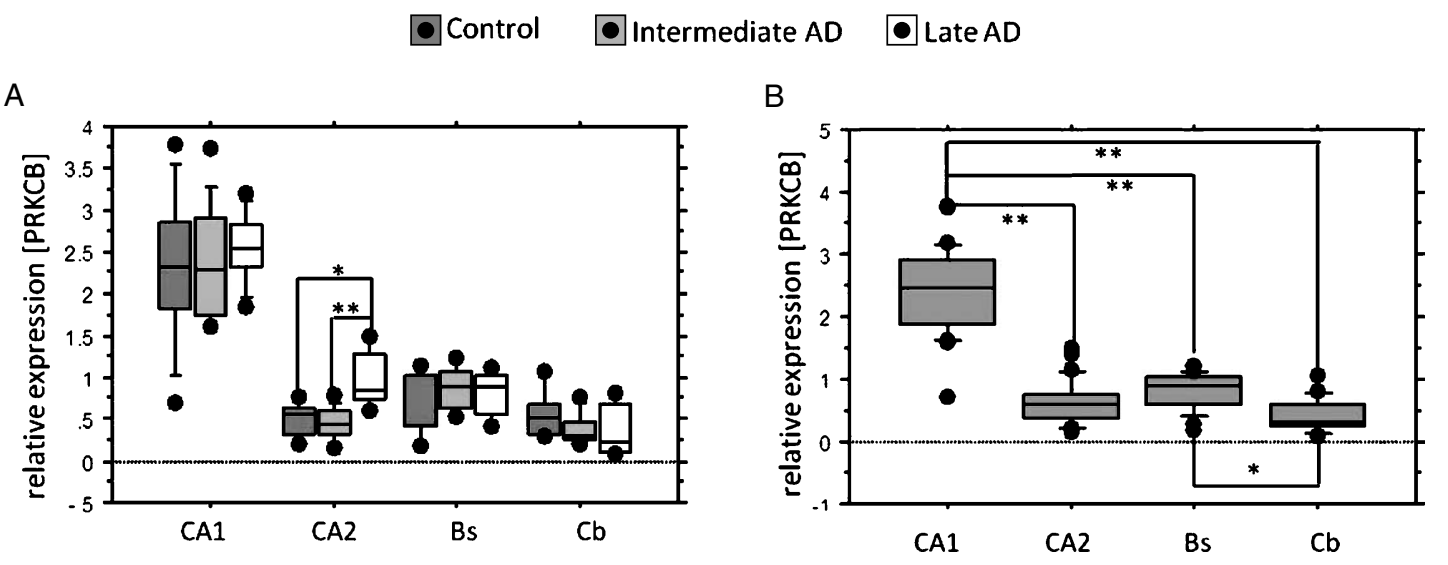

Fig. 2. A) Expression of PRKCB in granule cells from the cerebellum (Cb), pyramidal cells from the CA1 and CA2 regions of the hippocampus (CA1; CA2), and neurons from the nucleus tractus spinalis of the brain stem (Bs) of control (dark grey; $n=8$ for CA1, $n=7$ for CA2, $n=8$ for $\mathrm{Bs}$, and $n=6$ for $\mathrm{Cb}$ ), intermediate $\mathrm{AD}$ (light grey; $n=11$ for CA1, $n=11$ for CA2, $n=8$ for Bs, and $n=8$ for $\mathrm{Cb}$ ), and late $\mathrm{AD}$ (white; $n=8$ for $\mathrm{CA} 1, n=8$ for CA2, $n=7$ for Bs, and $n=7$ for $\mathrm{Cb}$ ) groups. (B) Region-specific gene expression levels independent of group ( $n=27$ for CA1, $n=26$ for CA2, $n=23$ for Bs, and $n=21$ for $\mathrm{Cb}$ ). Error bars indicate standard deviations. Statistical analysis was performed using ANOVA and the post hoc Scheffe test. ${ }^{*} p<0.05,{ }^{* *} p<0.001$.

of MAPK1 in the hyperphosphorylation of tau protein in AD has been hypothesized by other authors [24-26]. The increased expression of MAPK1 in CA1 pyramidal cells could be one factor contributing to the hyperphosphorylation of tau filaments.

Even though the CA2 region is not characterized by early intracellular tau accumulation or neuron loss in the context of $\mathrm{AD}, \mathrm{CA} 2$ pyramidal cells expressed identical levels of MAPK1 as CA1 pyramidal cells. Therefore, the elevated expression of MAPK1 cannot be the only explanation for the selective vulnerability of CA1 pyramidal cells to AD-related changes.

The role of PRKCB in AD development is ambiguous. Previous studies revealed a decrease in activated PRKCB in particulate fractions from AD brains and an increase in the soluble activated enzyme [27, 28]. These inconsistencies can be explained by the experimental protocol for analyzing tissue homogenates, whereas we focused on single-cell laser microdissection. Alldred et al. [29] also reported reduced PRKCB levels in a mouse model of AD. This finding could represent species-specific differences because the primate CA1 region consists of two layers: a superficial and a deep pyramidal cell layer [30]. The pyramidal cells of the deep layer, which is only present in primates, are prone to $\mathrm{AD}$ changes, whereas the cells of the superficial layer are chromophilic and look similar to CA2 pyramidal cells. In addition, the CA1 and CA2 borders are difficult to delineate in rodents. Ginsberg et al. [31] obtained different molecular signatures when analyzing single cells embedded in the surrounding tissue. Staining frozen sections with cre- syl violet guaranteed the harvest of neurons free of glial cells and surrounding neuropil.

The elevated PRKCB mRNA levels could represent reactions to acute and chronic stress, particularly in association with vascular events [32]. Interestingly, PRKCB activities are funneled into ERK/MAPK1 pathways via RAF and MEK [33]. Our pooled data indicate significantly higher levels of PRKCB in neurons from the nucleus tractus spinalis nervi trigemini compared to granule cells. However, exclusive elevation of PRKCB activity is not sufficient to cause AD-related changes. Only a combined elevation of MAPK1 and PRKCB-induced MAPK1 activity can trigger hyperphosphorylation of tau and intracellular deposition of NFT. Taken together, the results of the present study demonstrate that certain neuronal cell types in the brain display changes in essential signal transduction pathways. However, our data do not provide evidence of early involvement of the nucleus tractus spinalis nervi trigemini in the pathogenesis of AD. Altered neurophysiological signals can also be deduced from higher-order brainstem nuclei, including the parabrachial nuclei, which are located close to the nucleus tractus spinalis nervi trigemini that receive collaterals from the ascending spinothalamic tract, and also most likely from cutaneous vagal fibers. The parabrachial nuclei are affected early in AD [34].

We could not discriminate between control and AD cases, suggesting that alterations in signaling pathway components occur in both aging individuals and early in AD development. As the CA1 pyramidal cells of the hippocampus exhibit increased mRNA levels for both 
MAPK1 and PRKCB, we propose that an alteration in at least two, or even multiple, signal transduction pathways is required for the pathological changes observed in $\mathrm{AD}$.

\section{ACKNOWLEDGMENTS}

This work was supported by a grant from the Interdisciplinary Center for Clinical Research (IZKF), University of Wuerzburg, Germany. We thank Andrea Staudigel for excellent technical assistance during this study. We are indebted to Prof. Michael Sendtner (Institute for Clinical Neurobiology, Wuerzburg) and Prof. Albrecht Müller (Center for Experimental Molecular Medicine, Wuerzburg) for providing access to the Leica LMD microscope.

Authors' disclosures available online (http://www.jalz.com/disclosures/view.php?id=2015).

\section{REFERENCES}

[1] Braak H, Braak E (1991) Neuropathological stageing of Alzheimer-related changes. Acta Neuropathol 82, 239-259.

[2] Mizutani T, Shimada H (1991) Quantitative study of neurofibrillary tangles in subdivisions of the hippocampus. CA2 as a special area in normal aging and senile dementia of the Alzheimer type. Acta Pathol Jpn 41, 597-603.

[3] Davies DC, Horwood N, Isaacs SL, Mann DM (1992) The effect of age and Alzheimer's disease on pyramidal neuron density in the individual fields of the hippocampal formation. Acta Neuropathol 83, 510-517.

[4] Braak H, Braak E, Bohl J, Lang W (1989) Alzheimer's disease: Amyloid plaques in the cerebellum. J Neurol Sci 93, 277-287.

[5] Larner AJ (1997) The cerebellum in Alzheimer's disease. Dement Geriatr Cogn Disord 8, 203-209.

[6] Mavroudis IA, Fotiou DF, Adipepe LF, Manani MG, Njau SD, Psaroulis D, Costa VG, Baloyannis SJ (2010) Morphological changes of the human purkinje cells and deposition of neuritic plaques and neurofibrillary tangles on the cerebellar cortex of Alzheimer's disease. Am J Alzheimers Dis Other Demen 25, 585-591.

[7] Grudzien A, Shaw P, Weintraub S, Bigio E, Mash DC, Mesulam MM (2007) Locus coeruleus neurofibrillary degeneration in aging, mild cognitive impairment and early Alzheimer's disease. Neurobiol Aging 28, 327-335.

[8] Braak H, Del Tredici K (2011) The pathological process underlying Alzheimer's disease in individuals under thirty. Acta Neuropathol 121, 171-181.

[9] Grinberg LT, Rueb U, Heinsen H (2011) Brainstem: Neglected locus in neurodegenerative diseases. Front Neurol 2, 42.

[10] Attems J, Thomas A, Jellinger K (2012) Correlations between cortical and subcortical tau pathology. Neuropathol Appl Neurobiol 38, 582-590.

[11] Fallgatter AJ, Ehlis AC, Ringel TM, Herrmann MJ (2005) Age effect on far field potentials from the brain stem after transcutaneous vagus nerve stimulation. Int J Psychophysiol 56, 37-43.
[12] Fallgatter AJ, Neuhauser B, Herrmann MJ, Ehlis AC, Wagener A, Scheuerpflug P, Reiners K, Riederer P (2003) Far field potentials from the brain stem after transcutaneous vagus nerve stimulation. J Neural Transm 110, 14371443.

[13] Nomura S, Mizuno N (1983) Central distribution of efferent and afferent components of the cervical branches of the vagus nerve. A HRP study in the cat. Anat Embryol (Berl) 166, 1-18.

[14] Vogt C, Vogt O (1928) Die Grundlagen und die Teildisziplinen der mikroskopischen Anatomie des Zentralnervensystems. In Das Zentralnervensystem, Möllendorff W, ed. Verlag Von Julius Springer, Berlin, pp. 448-477.

[15] Hyman BT, Elvhage TE, Reiter J (1994) Extracellular signal regulated kinases. Localization of protein and mRNA in the human hippocampal formation in Alzheimer's disease. Am J Pathol 144, 565-572.

[16] Ferrer I, Blanco R, Carmona M, Puig B (2001) Phosphorylated mitogen-activated protein kinase (MAPK/ERK-P), protein kinase of $38 \mathrm{kDa}(\mathrm{p} 38-\mathrm{P})$, stress-activated protein kinase (SAPK/JNK-P), and calcium/calmodulin-dependent kinase II (CaM kinase II) are differentially expressed in tau deposits in neurons and glial cells in tauopathies. J Neural Transm 108, 1397-1415.

[17] Pei JJ, Braak H, An WL, Winblad B, Cowburn RF, Iqbal K, Grundke-Iqbal I (2002) Up-regulation of mitogen-activated protein kinases ERK1/2 and MEK1/2 is associated with the progression of neurofibrillary degeneration in Alzheimer's disease. Brain Res Mol Brain Res 109, 45-55.

[18] Pascale A, Amadio M, Govoni S, Battaini F (2007) The aging brain, a key target for the future: The protein kinase $\mathrm{C}$ involvement. Pharmacol Res 55, 560-569.

[19] Weeraratna AT, Kalehua A, Deleon I, Bertak D, Maher G, Wade MS, Lustig A, Becker KG, Wood 3rd W, Walker DG, Beach TG, Taub DD (2007) Alterations in immunological and neurological gene expression patterns in Alzheimer's disease tissues. Exp Cell Res 313, 450-461.

[20] Saitoh T, Horsburgh K, Masliah E (1993) Hyperactivation of signal transduction systems in Alzheimer's disease. Ann NY Acad Sci 695, 34-41.

[21] Grundemann J, Schlaudraff F, Haeckel O, Liss B (2008) Elevated alpha-synuclein mRNA levels in individual UVlaser-microdissected dopaminergic substantia nigra neurons in idiopathic Parkinson's disease. Nucleic Acids Res 36, e38.

[22] Ruijter JM, Ramakers C, Hoogaars WM, Karlen Y, Bakker O, van den Hoff MJ, Moorman AF (2009) Amplification efficiency: Linking baseline and bias in the analysis of quantitative PCR data. Nucleic Acids Res 37, e45.

[23] Zhu X, Castellani RJ, Takeda A, Nunomura A, Atwood CS, Perry G, Smith MA (2001) Differential activation of neuronal ERK, JNK/SAPK and p38 in Alzheimer disease: The 'two hit' hypothesis. Mech Ageing Dev 123, 39-46.

[24] Drewes G, Lichtenberg-Kraag B, Doring F, Mandelkow EM, Biernat J, Goris J, Doree M, Mandelkow E (1992) Mitogen activated protein (MAP) kinase transforms tau protein into an Alzheimer-like state. EMBO J 11, 2131-2138.

[25] Illenberger S, Zheng-Fischhofer Q, Preuss U, Stamer K, Baumann K, Trinczek B, Biernat J, Godemann R, Mandelkow EM, Mandelkow E (1998) The endogenous and cell cycledependent phosphorylation of tau protein in living cells: Implications for Alzheimer's disease. Mol Biol Cell 9, 14951512.

[26] Reynolds CH, Betts JC, Blackstock WP, Nebreda AR, Anderton BH (2000) Phosphorylation sites on tau identified by nanoelectrospray mass spectrometry: Differences in vitro between the mitogen-activated protein kinases ERK2, c-Jun 
N-terminal kinase and P38, and glycogen synthase kinase3beta. J Neurochem 74, 1587-1595.

[27] Cole G, Dobkins KR, Hansen LA, Terry RD, Saitoh T (1988) Decreased levels of protein kinase $\mathrm{C}$ in Alzheimer brain. Brain Res 452, 165-174.

[28] Masliah E, Cole G, Shimohama S, Hansen L, DeTeresa R, Terry RD, Saitoh T (1990) Differential involvement of protein kinase C isozymes in Alzheimer's disease. J Neurosci 10, 2113-2124.

[29] Alldred MJ, Duff KE, Ginsberg SD (2012) Microarray analysis of CA1 pyramidal neurons in a mouse model of tauopathy reveals progressive synaptic dysfunction. Neurobiol Dis $\mathbf{4 5}$, 751-762.

[30] Stephan H (1975) Allocortex. In Handbuch der mikroskopischen Anatomie des Menschen, vol 4, part 9, Bargmann W, ed. Springer, Berlin, pp. 1-998.
[31] Ginsberg SD, Alldred MJ, Che S (2012) Gene expression levels assessed by CA1 pyramidal neuron and regional hippocampal dissections in Alzheimer's disease. Neurobiol Dis 45, 99-107.

[32] Yan SF, Harja E, Andrassy M, Fujita T, Schmidt AM (2006) Protein kinase $\mathrm{C}$ beta/early growth response-1 pathway: A key player in ischemia, atherosclerosis, and restenosis. $J$ Am Coll Cardiol 48(9 Suppl 1), A47-A55.

[33] Kawakami T, Kawakami Y, Kitaura J (2002) Protein kinase C beta (PKC beta): Normal functions and diseases. $J$ Biochem 132, 677-682.

[34] Rüb U, Del Tredici K, Schultz C, Thal DR, Braak E, Braak $H$ (2001) The autonomic higher order processing nuclei of the lower brain stem are among the early targets of the Alzheimer's disease-related cytoskeletal pathology. Acta Neuropathol 101, 555-564. 